\title{
Changes in Drop Out Intentions: Implications of the Motivational Climate, Goal Orientations and Aspects of Self-Worth across a Youth Sport Season
}

\author{
Priscila Fabra $^{1}{ }^{\mathbb{D}}$, Isabel Castillo ${ }^{2} \mathbb{( D}$, Lorena González-García ${ }^{2, *} \mathbb{C}$, Joan L. Duda ${ }^{3}$ and Isabel Balaguer ${ }^{2}$ \\ 1 Department of Psychology, Universidad Europea de Valencia, 46010 Valencia, Spain; \\ priscila.fabra@universidadeuropea.es \\ 2 Department of Social Psychology, Faculty of Psychology, University of Valencia, 46010 Valencia, Spain; \\ isabel.castillo@uv.es (I.C.); isabel.balaguer@uv.es (I.B.) \\ 3 School of Sport, Exercise and Rehabilitation Sciences, University of Birmingham, Birmingham B15 2TT, UK; \\ j.1.duda@bham.ac.uk \\ * Correspondence: lorena.gonzalez@uv.es
}

\section{check for}

updates

Citation: Fabra, P.; Castillo, I.; González-García, L.; Duda, J.L.; Balaguer, I. Changes in Drop Out Intentions: Implications of the Motivational Climate, Goal Orientations and Aspects of Self-Worth across a Youth Sport Season. Sustainability 2021, 13, 13850. https://doi.org/10.3390/su132413850

Academic Editor:

Emilio Villa-González

Received: 9 November 2021

Accepted: 11 December 2021

Published: 15 December 2021

Publisher's Note: MDPI stays neutral with regard to jurisdictional claims in published maps and institutional affiliations.

Copyright: (C) 2021 by the authors. Licensee MDPI, Basel, Switzerland. This article is an open access article distributed under the terms and conditions of the Creative Commons Attribution (CC BY) license (https:// creativecommons.org/licenses/by/ $4.0 /)$

\begin{abstract}
The main objective of this work was to study the motivational antecedents of the intention to drop out of youth sport from the postulates of the achievement goal theory (AGT), placing special emphasis on the motivational climate that coaches create in their teams. Specifically, we analyzed whether changes in the perception of the motivational climate between the beginning and the end of the season predicted changes in players' goal orientations, whether these, in turn, predicted changes in self-esteem and contingent self-esteem, and finally, whether the latter predicted the intention to drop out. Participants in the study were 552 players $\left(M_{\mathrm{age}}=11.23, S D=1.14\right)$, who completed the questionnaires at the beginning and at the end of the season. The results of the longitudinal structural model presented acceptable goodness-of-fit indices and the relationships were significant in the expected direction according to the postulates of the AGT. This research provides evidence that AGT is a relevant theoretical model for the study of drop out in sport.
\end{abstract}

Keywords: drop out intentions; self-worth; goal orientations; motivational climate; young football players

\section{Introduction}

Sports participation during childhood and adolescence has numerous benefits for physical and mental health [1-7] and, in turn, increases the probability that young people continue to be physically active in adulthood [8-11]. These potential benefits of sport participation compelled several researchers to explore the factors that favor or hinder the regular practice of this type of physical activity during adolescence, as well as factors that prevent drop out [12-14]. Knowing the factors that lead to drop out is especially relevant at this stage of development, where there is a drastic decrease in participation rates in physical activity and sports [15-25].

In this research, a theoretical model is proposed to analyze the phenomenon of drop out through the intention of young football players to drop out of sports, as well as other specific aspects of the sports club in which they participate (i.e., the role of coaches).

One theory that emphasizes the role of coaches in young people's sporting experiences is the achievement goal theory (AGT) [26,27]. In this theory, it is considered central how athletes interpret success and failure through their conception of competence. It is argued that there are at least two ways of understanding and judging competence in achievement contexts such as sports. These two conceptions have been called ego orientation and task orientation. In ego orientation, the conception of competence is normative, meaning athletes judge whether or not they are competent by comparing their ability with that of others or by having certain standards of social comparison as a reference. These people 
strive to avoid showing a lack of competence when comparing themselves to others. The goal pursued, in this case, is to show that they are better than others- that is, to demonstrate a higher or equal competence, but with less effort. The person feels successful when this happens. In task orientation, the conception of competence is self-referenced, meaning the level of competence is judged based on a process of comparison with oneself, and the person feels successful when acting with mastery, when developing skills, or when task execution is improved. Therefore, in this case, the main objective is to acquire mastery, skills, or knowledge by exerting the maximum effort and giving the best of oneself. From a task-oriented perspective, competence is not fixed, per se, and can be increased with more effort [28].

The AGT argues that the social context influences the concept of competence through the goal structure defined by significant others [26-30]. In sports, coaches are the ones who establish achievement goals that are emphasized and adopted both in training and in competition through what is known as a motivational climate [26,29]. The perception of the motivational climate created by coaches influences how athletes judge their competence and define success [26,27], encouraging the adoption of certain achievement goals when they participate in their sport activity.

Previous studies and reviews [31-38] have shown that among the main reasons that young people indicate for dropping out their sports are those related to the coach, such as dislike of the coach or problems with the coach. The coach is a key figure in the way in which young people live their sports experience. The way coaches structure training and games, how they make decisions, the quality and quantity of feedback they provide in response to player performance, the techniques they use to motivate, etc., can have an impact on the emotional, cognitive, and behavioral responses of athletes [26,27].

In AGT, there are at least two dimensions of the motivational climate: a task-involving climate and an ego-involving climate [26,28,39]. In the task-involving climate, the coach emphasizes cooperative learning, improvement, effort, and the feelings that each one plays an important role in the team. In the ego-involving climate, the coach encourages rivalry within the team, shows unequal recognition of athletes based on their ability, and uses punishment when mistakes are made [39]. Following the concepts of competence described above, in the first climate, effort and improvement prevail using self-referenced criteria as indicators of success (task orientation), while in the second, a perception of competence linked to showing superiority over other athletes or to normative standards is favored (ego orientation). In this line, the results obtained in the research carried out in the sports context indicate that the task-involving climate is related or positively predicts the task orientation, and that the ego-involving climate is related or positively predicts the ego orientation [40-44]. Some research has also found that the task-involving climate is negatively related to ego orientation, and that the ego-involving climate is negatively related to task orientation $[45,46]$.

The development of well-being in sport is a fundamental piece to facilitate athletes' commitment to their activity [47], thus the current research has included self-esteem as an indicator of well-being and contingent self-esteem as one indicator of ill-being. Selfesteem, as an indicator of eudaimonic well-being, is defined as the global evaluation that the individual makes as a person [48]. On the other hand, contingent self-esteem refers to feelings about oneself that depend on reaching some standard of excellence or meeting certain interpersonal or intrapsychic expectations [49]. In this way, contingent self-esteem is defined by determinants or external environments, becoming contingent on the successes and failures that are achieved [50]. Contingent self-esteem depends on a constant evaluation process to be validated and, for this reason, it is unstable. Feelings of personal worth fluctuate in frequency and intensity according to the evaluation made of events, being vulnerable to obtaining negative results, the possible rejection of others, or the presence of negative personal characteristics [50].

The climate created by the coach, as well as the way of interpreting the athletes' competence, can be very relevant for self-esteem [51]. In task orientation, the perception 
of competence and the accompanying feelings of self-worth depend on self-referenced achievement. Given that the main objective when one is task-oriented is to master the task, learn more, and give the best of oneself (that is, factors that depend largely on oneself), it is expected that the task orientation will be positively related to self-esteem. Whereas in the case of ego orientation, since the criteria that define success are largely beyond one's control, this dimension is expected to be negatively related to self-esteem. Although previous research is limited, overall, it shows that task orientation is positively related to self-esteem [44,47,51-53].

The contexts in which ego-involving climates are fostered and where athletes are highly ego-oriented are conducive to athletes developing contingent self-esteem [53]. Taskoriented subjects perceive errors or failures as part of learning, and therefore contingent self-esteem will be less likely to occur since such situations will not influence feelings about themselves. In ego orientation, perceived competence and feelings of self-worth depend mainly on comparison with others and therefore depend on external factors that are not controllable and, in sports, generally unpredictable. Since it is highly difficult to constantly prove yourself better than others, feelings of worth will be in danger, and contingent self-esteem is more likely to appear. In the context of sports, no study has been found that pays attention to dispositional goal orientations as possible precursors of contingent self-esteem. Opening the range to variables closely related to orientations, a study by Reinboth and Duda [53] found that an ego-involving climate emerged as a positive predictor of contingent self-esteem.

Well-being in sports is a fundamental piece to facilitate athletes' commitment to their activity [47]. Children who have a positive conceptualization about themselves show higher levels of persistence and confidence [54], thus it could be expected that those with high self-esteem are more likely to persist in their sport participation. This is suggested by the results of the study by Atkins et al. [47], in which the self-esteem of adolescents positively predicted the intention to continue practicing their sport. However, Le Bars et al. [52] did not find a significant relationship with the intention to drop out. On the other hand, contingent self-esteem can lead to a maladaptive thinking pattern that damages well-being and jeopardizes sport continuation [53]. However, to date no study has been found that analyzes contingent self-esteem as a precedent of drop out in the context of sports or physical exercise. Due to the few studies that exist between these indicators of well-being (self-esteem) and of ill-being (contingent self-esteem) as predictors of sports drop out, these will be two of the antecedent variables of drop out in the present study.

Although we are increasingly aware of the importance of longitudinal studies, there are still few investigations with this methodology that include some of the variables that appear in this investigation. We know that longitudinal studies on sports drop out are of great importance since, in addition to providing theoretical knowledge about the processes that favor drop out and/or adherence, they also contribute to the design of practical interventions to change the motivational styles and antecedents of drop out with the intention of improving commitment to the sports activity. In this way, in this study, taking into account two measurement times for each variable, a theoretical model is tested where it is explored whether changes throughout the season in the perception of a task-involving climate and of an ego-involving climate predict changes in the task and ego orientations of the players, if changes in the goal orientations predict changes in self-esteem and contingent self-esteem, and, in turn, if these changes predict changes in players' intention to quit sports.

The proposed model based on the achievement goals theory is shown in Figure 1. It is hypothesized that, once the values of the variables are controlled at Time 1 (at the beginning of the season), at Time 2 (at the end of the season) H1: changes in the perceived task involving climate will positively predict changes in task orientation and negatively predict changes in ego orientation. H2: Changes in the perceived ego-involving climate will negatively predict changes in task orientation and positively predict changes in ego orientation. On the other hand, H3: it is expected that changes in task orientation will 
positively predict changes in self-esteem and negatively predict changes in contingent self-esteem, and that H4: changes in ego orientation will negatively predict changes in selfesteem and positively predict changes in contingent self-esteem. Finally, it is hypothesized that H5: changes in self-esteem will negatively predict changes in intention to drop out of sport, while changes in contingent self-esteem will positively predict changes in intention to drop out.

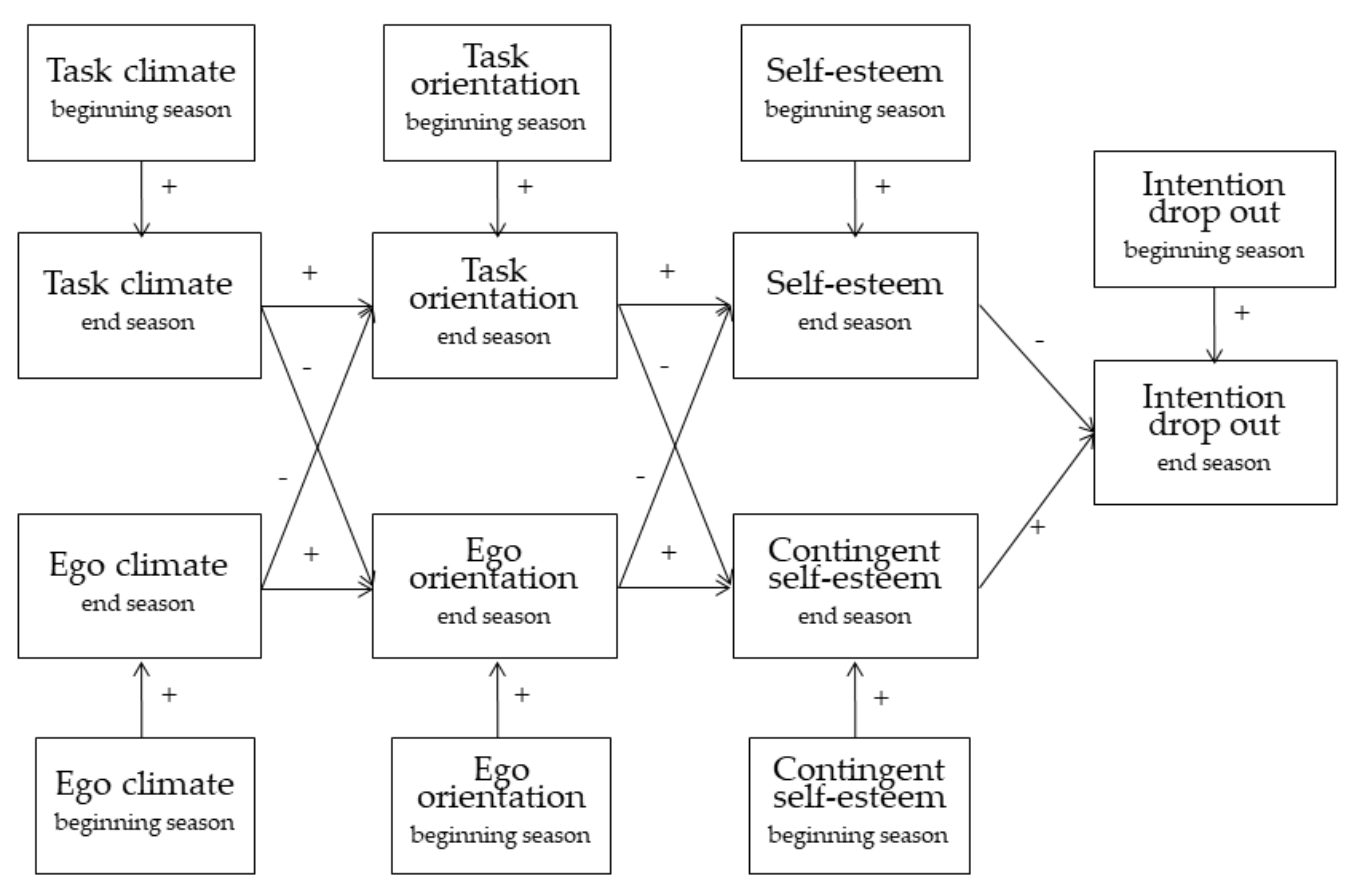

Figure 1. Hypothesized structural model of relationships, in Time 2 controlling Time 1, between perceived motivational climate, goal orientations, indicators of well- and ill-being, and intention to drop out.

\section{Materials and Methods}

\subsection{Participants}

The participants of the study were 552 young players $($ males $=508$; females $=44$; $M_{\text {age }}=11.23 ; S D=1.14 ;$ range $\left.=9-13\right)$, belonging to 53 football teams of the Valencian Football Federation (Spain). Of the total sample, 350 players (63.4\%) played under the age of 11 , and 202 players $(36.6 \%$ ) played under the age of 13 . The players practiced football with their team for an average of $4.32 \mathrm{~h}$ per week $(S D=1.01)$ and had been involved in their team for about 3.02 seasons $(S D=2.21)$.

\subsection{Instruments}

Sociodemographic characteristics. Gender, age, hours per week practicing football, and seasons they have been involved in their team were assessed.

Perceived task- and ego-involving motivational climate. The players' perception of the task and ego-involving climate created by the coaches in their teams was measured using the reduced Spanish version [55] of the Perceived Motivational Climate Questionnaire in Sport-2 (PMCSQ-2) [39]. In the present study, nine items were used to measure the perceived task involving climate created by the coach (e.g., "My coach acknowledged players who tried hard") and seven items were used to evaluate the perceived ego-involving climate (e.g., "My coach substituted players when they made a mistake"). The players were asked to think about what their first coach had normally done or said during the last 3-4 weeks. The response scale is a 5-point Likert-type, where 1 is strongly disagree and 5 is strongly agree. The validity and reliability of the scale has been confirmed in previous studies [41]. 
Players' goal orientation. The players goal orientations were measured using the Spanish version [56] of the Task and Ego Orientation Questionnaire in Sport (TEOSQ) [57,58]. The questionnaire consists of 13 items; seven items evaluate the players task orientation (e.g., "I feel most successful in football when I learn a new skill by trying hard") and six items assess the players' ego orientation (e.g., "I feel most successful in football when I can do better than my teammates"). The players were asked to indicate how much they agree or disagree with each statement in terms of when they feel successful when playing football. The response scale is a 5-point Likert-type, where 1 is strongly disagree and 5 is strongly agree. The validity and reliability of the scale has been confirmed in previous studies [41].

Self-esteem. The players' self-esteem was evaluated using the Spanish version [59] of the self-esteem subscale of the Self-Description Questionnaire 3 (SDQ-III) [60]. The subscale includes five items such as, for example, "Overall, I had a lot to be proud of". The players were asked to think about how they had generally felt in their daily life during the last 3-4 weeks. The response scale is a 5-point Likert-type, where 1 is strongly disagree and 5 is strongly agree. The validity and reliability of the scale has been confirmed in previous studies [59,61].

Contingent self-worth. The players contingent self-worth was measured using an adapted version of the Contingent Self-Worth in Sport Scale [53]. The initial version of this instrument consists of six items that assess contingent self-worth as a one-dimensional construct that reflects the degree to which athletes base their self-worth on their athletic performance and the degree to which not doing well in sports contributes to feelings of incompetence or lack of value as a person. In the present study, two new items were incorporated to improve the psychometric properties of the instrument. The final scale has eight items, and the response scale is a 5-point Likert-type, where 1 is strongly disagree and 5 strongly agree. An example item is "If I fail at football, I feel like a failure as a person". The players were asked to think about their performance in football during the last 3-4 weeks. Previous studies have confirmed internal consistency of the instrument [53].

Intentions to drop out. The players' intentions to drop out of football next season were assessed using four items designed to tap the degree to which football players intended to play or drop out of football next season [62]. Two items tapped intentions to drop out of football (e.g., "I intend to drop out of football at the end of this season") and two items tapped intentions to play football next season (e.g., "I plan to play football next season"). The intentions to drop out latent variable was obtained after reversing the two inversely worded items. The response scale is a 5-point Likert-type, where 1 is strongly disagree and is 5 strongly agree. The validity and reliability of the scale has been confirmed in previous studies [62].

\subsection{Procedure}

This research was conducted in accordance with international ethical standards, which are consistent with the guidelines of the American Psychological Association (APA) and the Declaration of Helsinki. Prior starting the research, approval was obtained from the Institutional Review Board of the University of Valencia (beneficiary no 3 to grant agreement 223600).

The sample of the study was selected through a randomized, stratified, and proportional process with respect to the total number of federated football players in under 11 and under 13 age categories of the Valencian Football Federation. This sample is part of a wider sample within the European project PAPA (Promoting Adolescent Physical Activity) [63].

Once the consent of the club leaders had been obtained, coaches, parents, and players included in the study's target sample were invited to participate by means of an informative letter, emphasizing that participation was voluntary.

The data from the questionnaires were collected at two points in time. At the beginning of the season, specifically between the end of October and the beginning of December (allowing at least one month from the beginning of the season to the shooting to allow the 
constitution of the corresponding team climate), and at the end of the season, between the end of April and the beginning of June. All players who participated in this study completed the questionnaires at both times and the same procedure was followed for both. The questionnaires were completed in the different grassroots soccer schools in a space set up for this purpose.

During the administration of the questionnaires, two researchers were always present to provide information on how to fill out the questionnaires and to resolve any doubts that might arise during the process, insisting that participants read all the items. They were also encouraged to answer honestly and were assured that their answers were confidential and that only those responsible for the research would have access to this information. Neither coaches, club managers, nor parents were allowed to be present during the data collection in order to guarantee the players' freedom and confidentiality when answering. The time required to fill out the scales was approximately $30 \mathrm{~min}$, varying according to the age of the athlete.

\subsection{Data Analysis}

First, descriptive (means and standard devitations) and realibility (Cronbach's alpha) analyses were performed for the scales in Time 1 and Time 2. Secondly, mean difference analyses were performed using the Student's $t$-test for related samples to check whether there were differences between the measurements taken at the two different time points. Lastly, a path analysis was tested to analyze the hypothesized relationships between the study variables. As the focus of attention was on the changes produced between the beginning of the season (Time 1) and the end of the season (Time 2) in the relationships proposed, the relationships models were performed with the variables of Time 2 controlling the effect of the same variables at Time 1. For this, the model included relationships between each of the variables at Time 2 and their corresponding measure at Time 1 . Since the model includes two measures for each variable (Time 1 and Time 2), the number of parameters proposed in the model is too high for the sample of participants available. For this reason, it is not recommended to work with observed indicators, and it is necessary to include the measures of the latent variables directly in the model. Therefore, once the measurement models were verified using the CFA for each of the scales, the SPSS Statistics V.24.0 statistical software (IBM Corp; Armonk, NY, USA) was used to verify that the observed indicators were satisfactorily related to their latent factors. Subsequently, the hypothesized structural equation model was analyzed using the maximum likelihood analysis with LISREL 8.80 [64], and the model adequacy was analyzed through different fit indices: the Root Mean Square Error of Approximation (RMSEA), Non-Normed Fit Index (NNFI), and Comparative Fit Index (CFI). CFI and NNFI values above 0.90 indicate an acceptable fit [65]. For RMSEA, values between 0.05 and 0.10 are considered acceptable (satisfactory: equal to or less than 0.08 [66].

\section{Results}

The results of the study showed that the young soccer players perceived that their coaches created a high task-involving climate and a low-medium ego-involving climate. Results also indicated that there were statistically significant differences between the mean value of these variables at the beginning of the season (Time 1) and at the end of the season (Time 2). Specifically, the perceived task-involving climate decreased in Time 2, and the perceived ego-involving climate increased in Time 2. Task orientation is high and ego orientation reflected a medium score. The players' perceived task orientation significantly decreased at Time 2, whereas the perceived ego orientation remained stable from Time 1 to Time 2. Regarding the indicators of well- and ill-being, results showed that the players report having a high self-esteem and a medium contingent self-esteem. The average score for both variables decreased at the end of the season. On the other hand, the intention to drop out, which started from a low average score, significantly increased at the end of the 
season (Table 1). The internal reliability coefficients were satisfactory for all the scales in both times.

Table 1. Means scores, standard deviation, reliabilities, and difference between time in all the variables of the study.

\begin{tabular}{cccccccc}
\hline & Alpha & $\begin{array}{c}\text { Time 1 } \\
\text { Mean }\end{array}$ & SD & Alpha & $\begin{array}{c}\text { Time 2 } \\
\text { Mean }\end{array}$ & SD & t \\
\hline Task-involving climate & 0.80 & 4.28 & 0.60 & 0.85 & 4.16 & 0.69 & $4.47 * *$ \\
Ego-involving climate & 0.75 & 2.37 & 0.87 & 0.82 & 2.46 & 0.92 & $-2.222^{*}$ \\
Task orientation & 0.84 & 4.45 & 0.61 & 0.86 & 4.35 & 0.68 & $3.22{ }^{* *}$ \\
Ego orientation & 0.83 & 2.89 & 1.04 & 0.87 & 2.87 & 1.10 & 0.57 \\
Self-esteem & 0.86 & 4.26 & 0.68 & 0.87 & 4.18 & 0.76 & $2.50 *$ \\
Contingent self-worth & 0.82 & 2.86 & 0.90 & 0.82 & 2.72 & 0.90 & $2.48^{*}$ \\
Intention to drop out & 0.71 & 1.51 & 0.69 & 0.73 & 1.74 & 0.80 & $-6.54 * *$ \\
\hline Note. Range variables: $1-5 .{ }^{* *} p<0.01 ;{ }^{*} p<0.05$. & & & & &
\end{tabular}

After the adjustment modification indices suggested an error covariance between the task-involving climate and the ego-involving climate, the model presented acceptable goodness-of-fit indices: $\chi^{2}(52)=162.99, p<0.01$; RMSEA $=0.086$; NNFI $=0.90 ; \mathrm{CFI}=0.94$. To facilitate the understanding of the data, Figure 2 only shows the significant relationships between the study variables. The changes in the task-involving climate positively predicted the changes in the task orientation and the changes in the ego-involving climate positively predicted the changes in players' ego orientation. Changes in task orientation positively predicted changes in self-esteem and negatively predicted changes in contingent selfesteem. On the other hand, changes in ego orientation positively predicted changes in contingent self-esteem. Finally, changes in self-esteem negatively predicted changes in intention to drop out and changes in contingent self-esteem positively predicted changes in intention to drop out. The proposed model explained $26 \%$ of the variance of task orientation, $29 \%$ of ego orientation, $36 \%$ of self-esteem, $27 \%$ of contingent self-esteem, and $24 \%$ of intention to drop out of their sport.

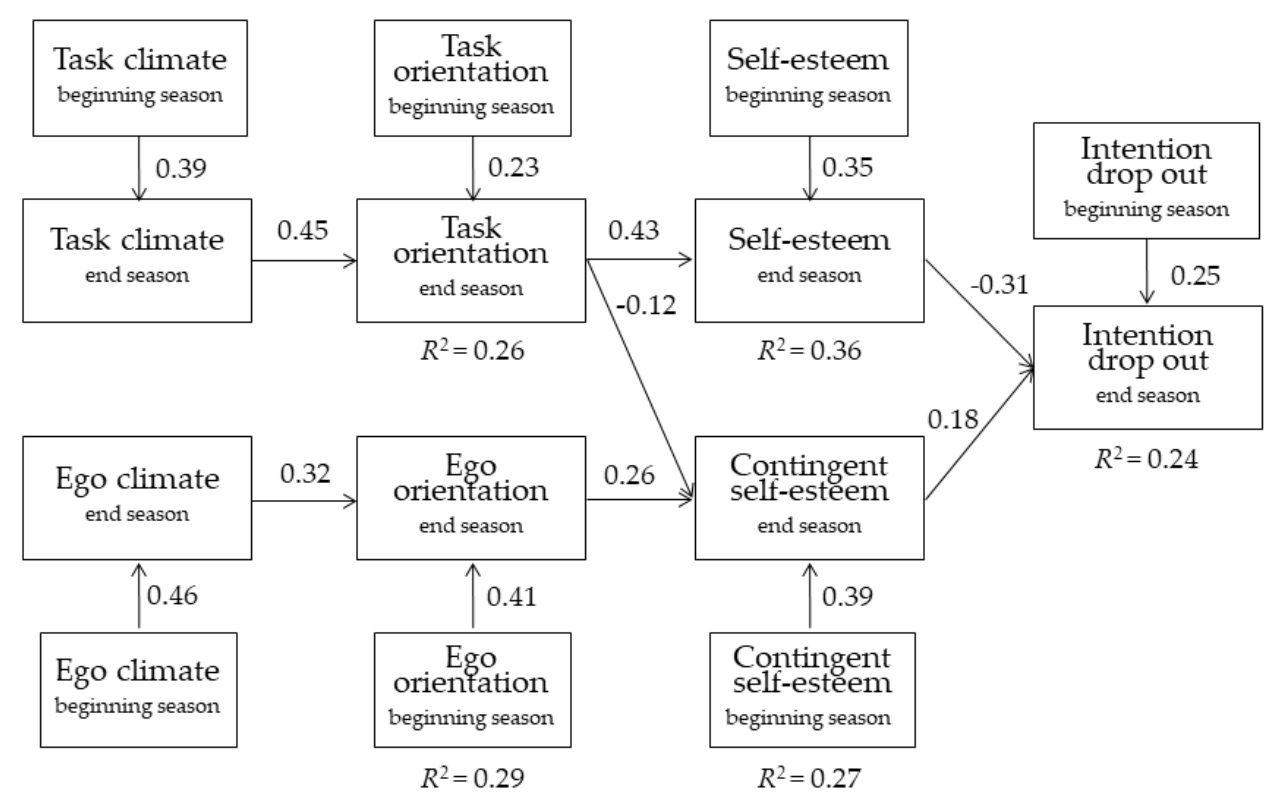

Figure 2. Standardized solution of the relationship model, in Time 2 controlling Time 1, between the perceived motivational climate, the goal orientations, the indicators of well- and ill-being, and the intention to drop out. Note: All the coefficients shown are significant $p<0.05$. To simplify reading, the non-significant relationships and error terms between task climate and ego climate are not presented visually $(-0.29)$. 


\section{Discussion}

Since we know that the quality of sports participation favors well-being and the intention to continue participating in sports, one of the challenges facing the research is to find the factors that favor intentions to continue sport participation and/or avoid sports drop out of young athletes. One of the variables that has been shown to be a good predictor of sports commitment and well-being is motivation, both in its individual and social aspects [67]. In our interest in knowing the personal and social factors that intervene in the development of well- or ill-being and in the intention to drop out, the objective of this work was to test a model for the prediction of the intention to drop out in a large sample of children and adolescents who practiced football, from AGT framework. It was tested whether changes throughout the season in the perception of motivational climate predicted changes in goal orientations, if the latter predicted changes in self-esteem and contingent self-esteem, and, finally, if the latter, in turn, predicted changes in the players' intention to drop out sport.

In line with the main postulates of the AGT, five hypotheses were raised. H1: Changes in the perception of the task involving climate will positively predict changes in task orientation and negatively predict changes in ego orientation. $\mathrm{H} 2$ : Changes in the perception of the ego involving climate will negatively predict changes in task orientation and positively changes in ego orientation. The results partially confirmed these first two hypotheses. On one hand, it was found that changes in the perception of the task-involving climate positively predicted changes in the task orientation of the players, but no changes were found in the ego orientation. On the other hand, changes in the perception of ego-involving climate positively predicted changes in ego orientation, but not in task orientation. These results are in line with previous research, in which a positive relationship between each climate dimension and its respective goal orientation was found, but a negative relationship with the other goal orientation was not found [42,44,68].

According to the AGT, the perception that coaches promote a task-involving climate encourages young football players to pursue goals such as personal improvement and strive to achieve them, without focusing on being better than others. However, if they perceive that coaches promote an ego-involving climate, players are more likely to adopt less adaptive goals, such as being better than or equal to others but making less effort.

The results confirmed the third hypothesis (H3), in which it was hypothesized that changes in task orientation would positively predict changes in self-esteem and negatively in contingent self-esteem. However, they offered partial support to the fourth hypothesis (H4) in which it was hypothesized that changes in ego orientation would negatively predict changes in self-esteem and positively in contingent self-esteem. In the latter case, it was found that changes in ego orientation positively predicted changes in contingent selfesteem, but contrary to expectations, their relationship with changes in self-esteem was not significant.

Taking these results into account, it should be noted that using self-referenced criteria to evaluate one's own competence and pursuing personal improvement as a goal in the context of sport may have important implications for the self-esteem of adolescents. On the contrary, athletes who are motivated to show that they are better than others can base their perception of their own value on performance in sport, with the danger that this may entail if their results are not superior to those of others, or if they fail to achieve these goals of superiority on an ongoing basis.

As in this study, most research has not found a direct relationship between ego orientation and self-esteem $[47,52,69,70]$ and some studies suggest that the relationship is indirect through perceived competence or ability [51,71].

Finally, the results confirmed the H5, since changes in the self-esteem of the players that occurred between the beginning and the end of the season, negatively predicted changes in intention to drop out. Contrarily, change in contingent self-esteem was a positive predictor of intention to drop out. Although the scientific evidence on these relationships is quite limited [47], the results found suggest the importance of young 
people valuing themselves both as people and as athletes, regardless of their achievements, thwarting, or limitations, to reach a continued participation in sport.

\section{Conclusions and Limitations}

In general, our findings invite us to underline the role that coaches play in the drop out phenomenon in grassroots football, since by creating more adaptive environments, they can promote adaptive motivational patterns that facilitate the optimal development of athletes and encourage commitment in sport. Coaches should create a task-involving climate during training and matches, proposing exercises or activities that promote cooperative learning, offering feedback that emphasizes learning the task, and personal improvement, giving importance to effort when they exercise and when games are played, as well as making them feel that each one of them is important to the team. In turn, coaches must know that it is equally important to avoid creating an ego-involving climate, so they should not make comparative comments or propose exercises or activities in a way that creates rivalry between teammates, treat players differently based on their ability, or take someone out of the game or otherwise punish them when they make mistakes.

Despite the contributions offered by the results of this study, there are some limitations that should be considered and overcome in future studies. On one hand, the type of longitudinal model that is tested requires including each of the variables studied twice-that is, both the measurement at Time 2 and at Time 1-to carry out their control. In this way, the number of variables included is so high that, although we have a sample of participants of an adequate size, it is not large enough to work with all the items and it was necessary to work with the observed variables.

On the other hand, some of the relationships raised in this study have limited or non-existent scientific evidence. That is why, in order to reach conclusions, it is necessary to continue exploring the role that these constructs play in the phenomenon of sports drop out.

Furthermore, despite the value of behavioral intention as a predictor of behavior [72], including drop out behavior in future studies would allow testing more complete models and knowing if the factors act in the same way on behavior as they do on intention.

In short, to obtain results in the challenge of maintaining sports participation in young people and avoiding the intention to drop out, it is necessary to continue researching, but, in turn, transfer the knowledge obtained to the reality of these athletes through intervention programs that help their coaches to use motivational strategies that promote the well-being of young athletes and the desire to continue participating in sport.

Author Contributions: Conceptualization, P.F., I.C., J.L.D. and I.B.; methodology, P.F., I.C., J.L.D. and I.B.; software, P.F., I.C. and I.B.; validation, P.F., I.C., L.G.-G., J.L.D. and I.B.; formal analysis, P.F. and I.C.; investigation, P.F., I.C., J.L.D. and I.B.; resources, I.B.; data curation, P.F. and I.C.; writing-original draft preparation, P.F., I.C., L.G.-G., J.L.D. and I.B.; writing-review and editing, P.F., I.C., L.G.-G., J.L.D. and I.B.; visualization, P.F. and I.C.; supervision, J.L.D. and I.B.; project administration, J.L.D. and I.B.; funding acquisition, P.F., J.L.D. and I.B. All authors have read and agreed to the published version of the manuscript.

Funding: The research leading to these results has received funding from the European Community's Seventh Framework Programme FP7/2007-2013 under grant agreement $n^{\circ} 223600$, and by the Generalitat Valenciana through the VALi+d program (2012/5541).

Institutional Review Board Statement: The study was conducted according to the guidelines of the Declaration of Helsinki, and approved by the Institutional Review Board (or Ethics Committee) of Universitat de València (protocol code 223600 approved on 21 December 2009).

Informed Consent Statement: Informed consent was obtained from all subjects involved in the study.

Data Availability Statement: Not applicable.

Conflicts of Interest: The authors declare no conflict of interest. 


\section{References}

1. Andersen, T.R.; Schmidt, J.F.; Nielsen, J.J.; Randers, M.B.; Sundstrup, E.; Jakobsen, M.D.; Andersen, L.L.; Suetta, C.; Aagaard, P.; Bangsbo, J.; et al. Effect of football or strength training on functional ability and physical performance in untrained old men. Scand. J. Med. Sci. Sports 2014, 24, 76-85. [CrossRef]

2. Andersen, T.R.; Schmidt, J.F.; Thomassen, M.; Hornstrup, T.; Frandsen, U.; Randers, M.B.; Hansen, P.R.; Krustrup, P.; Bangsbo, J. A preliminary study: Effects of football training on glucose control, body composition, and performance in men with type 2 diabetes. Scand. J. Med. Sci. Sports 2014, 24 (Suppl. S1), 43-56. [CrossRef] [PubMed]

3. Barbosa, S.; Urrea, A. Influencia del deporte y la actividad física en el estado de salud físico y mental: Una revisión bibliográfica. Rev. Katharsis 2018, 25, 141-159.

4. De Sousa, M.V.; Fukui, R.; Krustrup, P.; Pereira, R.M.R.; Silva, P.R.S.; Rodrigues, A.C.; De Andrade, J.L.; Hernandez, A.J.; Silva, M.E.R. Positive effects of football on fitness, lipid profile, and insulin resistance in Brazilian patients with type 2 diabetes. Scand. J. Med. Sci. Sports 2014, 24 (Suppl. S1), 57-65. [CrossRef] [PubMed]

5. $\quad$ Eime, R.M.; Young, J.A.; Harvey, J.T.; Charity, M.J.; Payne, W.R. A systematic review of the psychological and social benefits of participation in sport for children and adolescents: Informing development of a conceptual model of health through sport. Int. J. Behav. Nutr. Phys. Act. 2013, 10, 98. [CrossRef]

6. Faude, O.; Kerper, O.; Multhaupt, M.; Winter, C.; Beziel, K.; Junge, A.; Meyer, T. Football to tackle overweight in children. Scand. J. Med. Sci. Sports 2010, 20, 103-110. [CrossRef] [PubMed]

7. Malm, C.; Jakobsson, J.; Isaksson, A. Physical Activity and Sports-Real Health Benefits: A Review with Insight into the Public Health of Sweden. Sports 2019, 7, 127. [CrossRef]

8. Batista, M.B.; Romanzini, C.L.P.; Barbosa, C.C.L.; Shigaki, G.B.; Romanzini, M.; Ronque, E.R.V. Participation in sports in childhood and adolescence and physical activity in adulthood: A systematic review. J. Sports Sci. 2019, 37, 2253-2262. [CrossRef]

9. Bélanger, M.; Sabiston, C.M.; Barnett, T.A.; O'Loughlin, E.; Ward, S.; Contreras, G.; O'Loughlin, J. Number of years of participation in some, but not all, types of physical activity during adolescence predicts level of physical activity in adulthood: Results from a 13-year study. Int. J. Behav. Nutr. Phys. Act. 2015, 12, 76. [CrossRef]

10. Kjønniksen, L.; Torsheim, T.; Wold, B. Tracking of leisure-time physical activity during adolescence and young adulthood: A 10-year longitudinal study. Int. J. Behav. Nutr. Phys. Act. 2008, 5, 69. [CrossRef]

11. Telama, R.; Yang, X.; Hirvensalo, M.; Raitakari, O. Participation in Organized Youth Sport as a Predictor of Adult Physical Activity: A 21-Year Longitudinal Study. Pediatr. Exerc. Sci. 2006, 18, 76-88. [CrossRef]

12. Boiché, J.C.; Sarrazin, P. Proximal and distal factors associated with dropout versus maintained participation in organized sport. J. Sports Sci. Med. 2009, 8, 9-16. [PubMed]

13. Cervello, E.; Escartí, A.; Guzmán, J.F. Youth sport dropout from the achievement goal theory. Psicothema 2007, 19, 65-71. [PubMed]

14. Fraser-Thomas, J.; Côté, J.; Deakin, J. Understanding dropout and prolonged engagement in adolescent competitive sport. Psychol. Sport Exerc. 2008, 9, 645-662. [CrossRef]

15. Bélanger, M.; Gray-Donald, K.; O’Loughlin, J.; Paradis, G.; Hanley, J. When Adolescents Drop the Ball: Sustainability of Physical Activity in Youth. Am. J. Prev. Med. 2009, 37, 41-49. [CrossRef]

16. Bruner, M.W.; Chad, K.E.; Beattie-Flath, J.A.; Humbert, M.L.; Verrall, T.C.; Vu, L.; Muhajarine, N. Examination of physical activity in adolescents over the school year. Pediatr. Exerc. Sci. 2009, 21, 421-435. [CrossRef] [PubMed]

17. Roman, B.; Serra-Majem, L.; Ribas-Barba, L.; Perez-Rodrigo, C.; Aranceta, J. How many children and adolescents in Spain comply with the recommendations on physical activity? J. Sports Med. Phys. Fitness 2008, 48, 380-387.

18. Chillón, P.; Ortega, F.B.; Ruiz, J.; Pérez, I.J.; Martín-Matillas, M.; Valtueña, J.; Gómez_Martínez, S.; Redondo, C.; Rey-López, J.P.; Castillo, M.J.; et al. Socio-economic factors and active commuting to school in urban Spanish adolescents: The AVENA study. Eur. J. Public Health 2009, 19, 470-476. [CrossRef]

19. Currie, C.; Gabbain, S.N.; Godeau, E.; Roberts, C.; Smith, R.; Currie, D.; Pickett, W.; Richter, M.; Morgan, A.; Barnekow, V. Inequalities in Young People's Health: HBSC International Report from the 2005/2006 Survey; WHO Regional Office for Europe: Copenhagen, Denmark, 2008.

20. Dumith, S.C.; Gigante, D.P.; Domingues, M.R.; Kohl, H.W. Physical activity change during adolescence: A systematic review and a pooled analysis. Int. J. Epidemiol. 2011, 40, 685-698. [CrossRef]

21. Eime, R.; Harvey, J.T.; Charity, M.; Payne, W. Population levels of sport participation: Implications for sport policy. BMC Public Health 2016, 16, 752. [CrossRef]

22. García-Calvo, T.; Cervelló, E.; Jiménez, R.; Iglesias, D.; Moreno-Murcia, D. Using self-determination theory to explain sport persistence and dropout in adolescent athletes. Span. J. Psychol. 2010, 13, 677-684. [CrossRef] [PubMed]

23. Knuth, A.G.; Hallal, P.C. Temporal Trends in Physical Activity: A Systematic Review. J. Phys. Act. Health 2009, 6, 548-559. [CrossRef]

24. Metcalf, B.S.; Hosking, J.; Jeffery, A.N.; Henley, W.E.; Wilkin, T.J. Exploring the Adolescent Fall in Physical Activity: A 10-yr cohort study (EarlyBird 41). Med. Sci. Sports Exerc. 2015, 47, 2084-2092. [CrossRef] [PubMed]

25. Møllerløkken, N.E.; Lorås, H.; Pedersen, A. V A systematic review and meta-analysis of dropout rates in youth soccer. Percept. Mot. Skills 2015, 121, 913-922. [CrossRef] [PubMed]

26. Ames, C. Classrooms: Goals, structures, and motivation. J. Educ. Psychol. 1992, 84, 261-271. [CrossRef]

27. Nicholls, J.G. The Competitive Ethos and Democratic Education; Harvard University Press: Cambridge, UK, 1989. 
28. Nicholls, J.G. Conceptions of ability and achievement motivation. In Research on Motivation in Education: Students Motivation; Ames, R., Ames, C., Eds.; Academic Press: New York, NY, USA, 1984.

29. Ames, C. Achievement goals and the classroom motivational climate. In Student Perceptions in the Classroom; Schunk, D., Meece, J., Eds.; Lawrence Erlbaum Associates: Hillsdale, NJ, USA, 1992.

30. Dweck, C.S. Motivational processes affecting learning. Am. Psychol. 1986, 41, 1040-1048. [CrossRef]

31. Hassan, A.-R.; Lam, M.H.S.; Ku, S.; Li, H.C.W.; Lee, K.Y.; Ho, E.; Flint, S.W.; Wong, A.S.W. The reasons of dropout of sport in Hong Kong school athletes. Health Psychol. Res. 2017, 5, 6766. [CrossRef]

32. Keathley, K.; Himelein, M.J.; Srigley, G. Youth soccer participation and withdrawal: Gender similarities and differences. J. Sport Behav. 2013, 36, 171-188.

33. Macarro, J.; Romero, C.; Torres, J. Reasons why higher secondary school students in the province of Granada dropout of sports and organized physical activities. Rev. Educ. 2010, 353, 495-519.

34. Molinero, O.; Salguero, A.; Tuero, C.; Álvarez, E.; Márquez, S. Dropout reasons in young Spanish athletes: Relationship to gender, type of sport and level of competition. J. Sport Behav. 2006, 29, 255-269.

35. Molinero, O.; Salguero, A.; Álvarez, E.; Márquez, S. Reasons for dropout in youth soccer: A comparison with other team sports. Eur. J. Hum. Mov. 2009, 22, 21-30.

36. Monteiro, D.; Cid, L.; Marinho, D.A.; Moutão, J.; Vitorino, A.; Bento, T. Determinants and Reasons for Dropout in Swimming -Systematic Review. Sports 2017, 5, 50. [CrossRef] [PubMed]

37. Rottensteiner, C.; Laakso, L.; Pihlaja, T.; Konttinen, N. Personal Reasons for Withdrawal from Team Sports and the Influence of Significant others among Youth Athletes. Int. J. Sports Sci. Coach. 2013, 8, 19-32. [CrossRef]

38. Schlesinger, T.; Löbig, A.; Ehnold, P.; Nagel, S. What is influencing the dropout behaviour of youth players from organised football? Ger. J. Exerc. Sport Res. 2018, 48, 176-191. [CrossRef]

39. Newton, M.; Duda, J.L.; Yin, Z. Examination of the psychometric properties of the Perceived Motivational Climate in Sport Questionnaire-2 in a sample of female athletes. J. Sports Sci. 2000, 18, 275-290. [CrossRef]

40. Gjesdal, S.; Haug, E.M.; Ommundsen, Y. A Conditional Process Analysis of the Coach-Created Mastery Climate, Task Goal Orientation, and Competence Satisfaction in Youth Soccer: The Moderating Role of Controlling Coach Behavior. J. Appl. Sport Psychol. 2018, 31, 203-217. [CrossRef]

41. Granero-Gallegos, A.; Gómez-López, M.; Rodríguez-Suárez, N.; Abraldes, J.A.; Alesi, M.; Bianco, A. Importance of the Motivational Climate in Goal, Enjoyment, and the Causes of Success in Handball Players. Front. Psychol. 2017, 8, 2081. [CrossRef]

42. Harwood, C.G.; Keegan, R.; Smith, J.M.; Raine, A.S. A systematic review of the intrapersonal correlates of motivational climate perceptions in sport and physical activity. Psychol. Sport Exerc. 2015, 18, 9-25. [CrossRef]

43. Ingrell, J.; Johnson, U.; Ivarsson, A. Achievement goals in youth sport and the influence of coaches, peers, and parents: A longitudinal study. J. Hum. Sport Exerc. 2020, 15, 570-590. [CrossRef]

44. Lochbaum, M.; Zazo, R.; Çetinkalp, Z.K.; Wright, T.; Graham, K.-A.; Konttinen, N. A meta-analytic review of achievement goal orientation correlates in competitive sport: A follow-up to Lochbaum et al. (2016). Kinesiology 2016, 48, 159-173. [CrossRef]

45. Newton, M.L. The Effects of Differences in Perceived Motivational Climate and Goal Orientations on Motivational Responses of Female Volleyball Players; Purdue University: West Lafayette, IN, USA, 1994.

46. Gonzalez, M.Z.; San José, S.P.; González, M.V. Motivational analysis during one season in female football in Castilla y León (Spain) (Análisis motivacional durante una temporada de fútbol femenino en Castilla y León (España)). Retos 2020, 40, 8-17. [CrossRef]

47. Atkins, M.R.; Johnson, D.M.; Force, E.C.; Petrie, T.A. Peers, parents, and coaches, oh my! The relation of the motivational climate to boys' intention to continue in sport. Psychol. Sport Exerc. 2015, 16, 170-180. [CrossRef]

48. Marsh, H.W.; Parker, J.; Barnes, J. Multi-dimensional adolescent self-concepts: Their relationship to age, sex and academic measures. Am. Educ. Res. J. 1985, 22, 422-444. [CrossRef]

49. Deci, E.L.; Ryan, R.M. Human autonomy: The basis for true self-esteem. In Efficacy, Agency, and Self-Esteem; Kemis, M., Ed.; Plenum: New York, NY, USA, 1995.

50. Bermúdez, J.; Pérez-García, A.M.; Ruiz, J.A.; Sanjuán, P.; Rueda, B. Psicologia de La Personalidad; UNED: Madrid, Spain, 2013.

51. Kavussanu, M.; Harnisch, D.L. Self-esteem in children: Do goal orientations matter? Br. J. Educ. Psychol. 2000, 70, 229-242. [CrossRef]

52. Le Bars, H.; Gernigon, C.; Ninot, G. Personal and contextual determinants of elite young athletes' persistence or dropping out over time. Scand. J. Med. Sci. Sports 2009, 19, 274-285. [CrossRef]

53. Reinboth, M.; Duda, J.L. Motivational climate, perceived ability, and athletes' psychological and physical well-being. Sport Psychol. 2004, 18, 237-251. [CrossRef]

54. Baumeister, R.F.; Campbell, J.D.; Krueger, J.I.; Vohs, K.D. Does High Self-Esteem Cause Better Performance, Interpersonal Success, Happiness, or Healthier Lifestyles? Psychol. Sci. Public Interest 2003, 4, 1-44. [CrossRef] [PubMed]

55. Balaguer, I.; Castillo, I.; Duda, J.L. Interrelaciones entre el clima motivacional y la cohesión en futbolistas cadetes. eduPsykhé 2003, 2, 243-258.

56. Balaguer, I.; Castillo, I.; Tomás, I. Análisis de las propiedades psicométricas del Cuestionario de Orientación al Ego y a la Tarea en el Deporte (TEOSQ) en su traducción al castellano. Psicológica 1996, 17, 71-81. 
57. Duda, J.L. The relationship between task and ego orientation and the perceived purpose of sport among male and female high school athletes. J. Sport Exerc. Psychol. 1989, 11, 318-335. [CrossRef]

58. Duda, J.L.; Nicholls, J.G. Dimensions of achievement motivation in schoolwork and Sport. J. Educ. Psychol. 1992, 84, 290-299. [CrossRef]

59. Balaguer, I.; Castillo, I.; Duda, J.L. Apoyo a la autonomía, satisfacción de las necesidades, motivación y bienestar en deportistas de competición: Un análisis de la teoría de la autodeterminación. Rev. Psicol. Deport. 2008, 17, 123-139.

60. Marsh, H.W.; Richards, G.E.; Johnson, S.; Roche, L.; Tremayne, P. Physical Self-Description Questionnaire: Psychometric properties and a multitrait multimethod analysis of relations to existing instruments. J. Sport. Exerc. Psychol. 1994, 16, 270-305. [CrossRef]

61. Tietjens, M.; Freund, P.A.; Büsch, D.; Strauss, B. Using mixture distribution models to test the construct validity of the Physical Self-Description Questionnaire. Psychol. Sport Exerc. 2012, 13, 598-605. [CrossRef]

62. Quested, E.; Ntoumanis, N.; Viladrich, C.; Haug, E.; Ommundsen, Y.; Van Hoye, A.; Mercé, J.; Hall, H.K.; Zourbanos, N.; Duda, J.L. Intentions to drop-out of youth soccer: A test of the basic needs theory among European youth from five countries. Int. J. Sport Exerc. Psychol. 2013, 11, 395-407. [CrossRef]

63. Duda, J.L.; Quested, E.; Haug, E.; Samdal, O.; Wold, B.; Balaguer, I.; Castillo, I.; Sarrazin, P.; Papaioannou, A.; Ronglan, L.T.; et al. Promoting Adolescent health through an intervention aimed at improving the quality of their participation in Physical Activity (PAPA): Background to the project and main trial protocol. Int. J. Sport Exerc. Psychol. 2013, 11, 319-327. [CrossRef]

64. Jöreskog, K.G.; Sörbom, D. LISREL 8.80 [computer software]; Scientific Software International, Inc.: Lincolnwood, IL, USA, 2003.

65. Hu, L.T.; Bentler, P. Evaluating model fit. In Structural Equation Modeling: Concepts, Issues, and Applications; Hoyle, R.H., Ed.; Sage: Thousand Oaks, CA, USA, 1995; pp. 77-99.

66. Cole, D.A.; Maxwell, S.E. Multitrait-Multimethod Comparisons Across Populations: A Confirmatory Factor Analytic Approach. Multivar. Behav. Res. 1985, 20, 389-417. [CrossRef] [PubMed]

67. Sarrazin, P.; Vallerand, R.; Guillet, E.; Pelletier, L.; Cury, F. Motivation and dropout in female handballers: A 21-month prospective study. Eur. J. Soc. Psychol. 2002, 32, 395-418. [CrossRef]

68. Vazou, S. Variations in the perceptions of peer and coach motivational climate. Res. Q. Exerc. Sport 2010, 81, 199-211. [CrossRef]

69. Guinn, B.; Vincent, V.; Semper, T.; Jorgensen, L. Activity Involvement, Goal Perspective, and Self-Esteem among Mexican American Adolescents. Res. Q. Exerc. Sport 2000, 71, 308-311. [CrossRef]

70. Treasure, D.C.; Biddle, S. Antecedents of physical self-worth and global self-esteem: Influence of achievement goal orientations and perceived ability. In Proceedings of the The Annual Conference of the North American Society of the Psychology of Sport and Physical Activity, Denver, CO, USA, 11-13 June 1997.

71. Gjesdal, S.; Appleton, P.R.; Ommundsen, Y. Both the "What" and "Why" of Youth Sports Participation Matter: A Conditional Process Analysis. Front. Psychol. 2017, 8, 659. [CrossRef] [PubMed]

72. Ajzen, I.; Fishbein, M. Understanding Attitudes and Predicting Social Behavior; Prentice-Hall: Englewood Cliffs, NJ, USA, 1980. 